\title{
THE SURFACE TENSION OF BLOOD SERUM, AND THE DETERMINATION OF THE SURFACE TENSION OF BIOLOGICAL FLUIDS
}

\author{
BY HENRY N. HARKINS AND WILLIAM D. HARKINS \\ (From the Department of Chemistry, University of Chicago, Chicago)
}

(Received for publication January 4, 1929)

\section{INTRODUCTION}

This investigation was undertaken in order to obtain a more exact knowledge of the surface tension of undiluted blood serum, and its variation under various clinical conditions, than is given by the work reported earlier by others (1-12). It was found that practically all previous investigators have made errors in the experimental procedure or in the calculation of their results, usually in both, of such a high magnitude as to make their data almost entirely worthless. Thus a new field is opened up for future investigation.

The mean value obtained for the surface tension of undiluted normal blood serum is 52 dynes per centimeter at $20^{\circ}$ and 48 dynes at $37^{\circ} \mathrm{C}$. The result at the higher temperature agrees moderately well with the mean value found by Morgan and Woodward (7), but it is known that the method by which their results were calculated gives values which are too low. The average of all of their values at $37^{\circ}$ is 45.5 while the average of all of our results is 46.2. However, their work represents a great forward step, as it is of a much higher degree of accuracy than that of any of the other earlier investigators. Almost all of the values obtained by others are of an altogether different order of magnitude, since they are from 10 to 20 dynes too high.

The worthlessness of much of the work is due to an altogether incorrect assumption, which is that if only relative values are desired no attention needs to be paid to the theory of the method used. Thus the method in which the number of drops given by a certain volume of the liquid with a certain tip (drop number method) is supposed to be inversely proportional to the surface tension, is practically useless, 
as is the ring method as commonly used. The determination of the capillary height is the most accurate of all known methods for the determination of the surface tension of pure liquids which are not too viscous. When used with blood serum, and with most other biological liquids, it has, however, the disadvantage that the film at the surface often prevents the attainment of capillary-hydrostatic equilibrium and it may affect the angle of contact. The bubble pressure method suffers from the disadvantage that as usually applied the experimental procedure does not agree with the conditions set up by the theory of the method. A much greater disadvantage is that it is difficult or almost impossible to hold the bubble at its maximum pressure for the considerable time necessary to establish equilibrium between the interior of the serum and its surface.

A careful consideration of all of the available methods seemed to indicate that the best results for such liquids may be obtained by the special modification of the drop weight method described later in the paper. The drop weight method avoids difficulties which relate to the angle of contact and the measurements are much less affected by the surface viscosity than when the capillary height method is used.

THE DROP WEIGHT APPARATUS FOR THE DETERMINATION OF SURFACE TENSION OF BLOOD SERUM AND OTHER BIOLOGICAL LIQUIDS

The apparatus used for the determination of the surface tension of blood serum is a modified form of the drop weight apparatus of Harkins and Brown (13), which resembles in general design that of Morgan (14).

The apparatus (fig. 1) consists essentially of an inverted capillary U-tube, suspended in a metal box $(B)$, which is provided with glass windows in front of and back of the tip from which the drop of serum is suspended. One limb of this inverted U-tube dips into a reservoir $(S)$ of the serum. The other limb ends in the tip which is held by a stopper of glass or metal in the weighing bottle $(V)$, in which the drops are collected as they fall.

Each drop is pulled over, until it attains the maximum size consistent with stability, by the action of suction applied through the metal tube $(A)$, and the drop is held at this maximum extension for seven minutes before it is allowed to fall. 


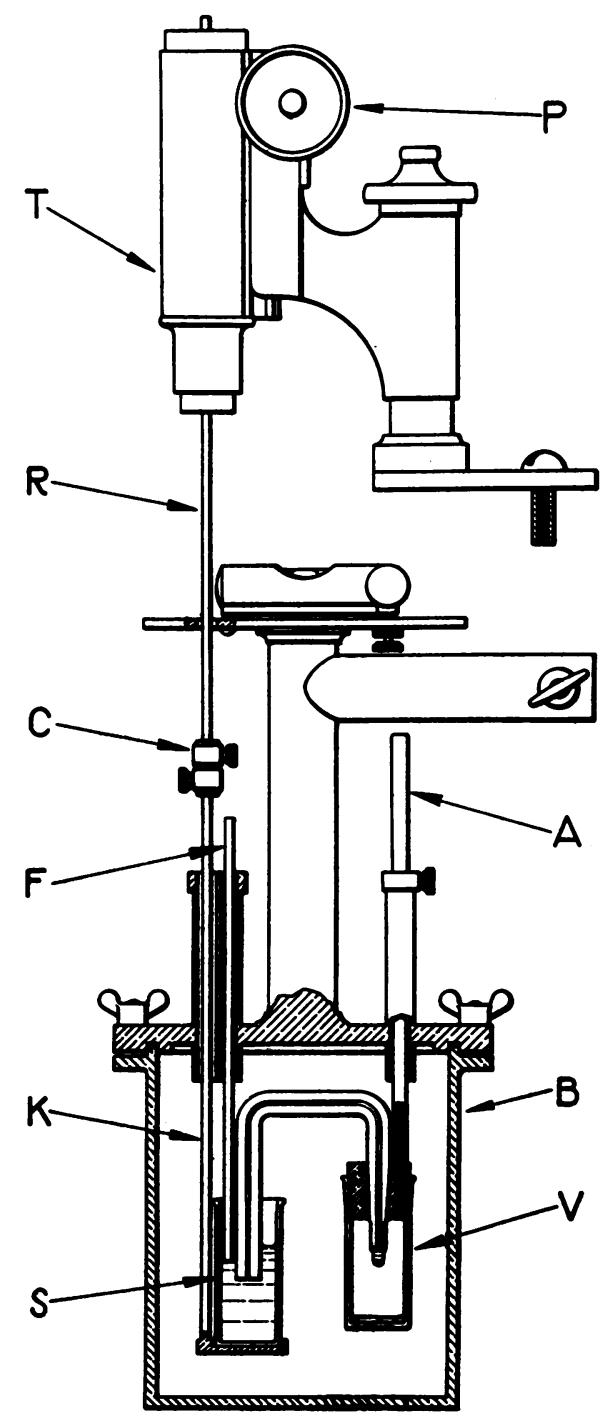

Fig. 1. Apparatus for the Determination of the Surface Tension of Blood Serum and Other Biological Liquids by the Drop Weight Method

$V$, weighing bottle under tip for collecting drops; $S$, reservoir for serum; $K C R$, rod for controlling the speed of drop formation; $P$, rack and pinion for adjusting height of $\operatorname{rod} R ; F$; tube for saturating serum with alveolar air; $A$, suction tube, and $B$, box for keeping out water of thermostat. The tip of pyrex glass is circular, and shows no flaws in its edge under a magnification of $20 \times$. The bottom of the tip is first ground off plane. Then a circular piece of glass of the same diameter as the tip is sealed over it by means of de Khotinsky cement. The sides of the tip are then ground down to the required diameter in a precision lathe. The tip is rotated in one direction, and it is ground by a high speed, very fine, disc of carborundum, which rotates in the opposite direction and is finally given a high polish by means of rouge. When the cement is melted a tip ground properly in this way is found to be circular and perfectly sharp. Eight different diameters of the tip are measured to $0.0001 \mathrm{~cm}$. each. 
The glass tube $(F)$ is used for the aeration of the serum with alveolar air, as described in the section on aeration, or with another gas.

During a determination the metal box $(B)$ is kept entirely immersed in the water of a thermostat at the proper temperature $\pm 0.01^{\circ}$.

It is extremely important that the serum in $(S)$ be adjusted to the level requisite to hold the drop at exactly full extension for the seven minute period. This is done by means of the rod $(R)$, which controls the level of the reservoir $(S)$. For the work described in the present paper this level was adjusted by hand, and the delicate control of the drop was effected by properly varying the suction applied at $(A)$.

However, the difficulty of controlling the drop in this way led to the method of control described in the next paragraph.

CONTROL OF THE DROP AND VARIATION OF THE DROP WEIGHT WITH TIME

Biological liquids contain in general surface-active substances, and the surface whose tension is being measured must be kept fully formed sufficiently long to allow equilibrium between the surface and the interior of the liquid to be attained. With aqueous solutions of decylic acid the minimum period of full extension is more than thirty minutes. With blood serum the surface tension falls for several minutes, and rises again if the surface becomes older than about seven minutes. This actual or apparent increase may be due to the formation of a solid film which does not represent a true condition of equilibrium with the interior of the liquid.

A delicate adjustment of the pressure in the drop, which determines its extension, is obtained by suspending the rod $(R)$ from the bar $(T)$ which is raised and lowered by a rachet and pinion. For this purpose a microscope stand with a coarse and fine adjustment is ideal.

The "full extension of the drop" can be determined only by trial. The telescope of a cathetometer is levelled and the height of the telescope is so adjusted that the horizontal cross hair and the bottom of the 'drop at full extension appear coincident. The level of the serum in $(S)$ is so adjusted that the bottom of the drop will remain at this level for the desired period (of seven minutes). Several trials are necessary, even with the experienced worker. A common error is to consider that the level of full extension lies higher than is actually the case. To avoid this the level of the cross hair is lowered slightly, 
and an endeavor is made to adjust the level of the bottle $(S)$ in such a way that the drop will not fall. If this is possible, the preceding level was too high.

An error in the opposite direction is apt to arise due to the decrease of the surface tension as the surface-active substance diffuses into the surface from the body of the liquid. The length of the drop at "full extension" for the higher surface tension is greater than that for the lowest, or equilibrium tension. This makes it necessary, if a seven minute period is to be allowed, to determine the full extension at the end of this period.

TABLE 1

Comparison of the weights of drop hell at almost full extension for seven minutes and those held for a shorter period

\begin{tabular}{c|c|c|c|c}
\hline Patient & Time & Drop weight & Time & Drop weight \\
\hline & minuies & & minuies & \\
D & $\frac{1}{2}$ & 0.06260 & 7 & 0.05393 \\
F & $1 \frac{1}{1}$ & 0.06070 & 7 & 0.05520 \\
F & 1 & 0.05510 & 7 & 0.05440 \\
S & & & 7 & 0.04770 \\
S & 1 & 0.05860 & 7 & 0.04780 \\
S & & & 7 & 0.04932 \\
\hline
\end{tabular}

The tip used in the work in this and later tables on patients $\mathrm{D}$ to $\mathrm{K}$ inclusive has a diameter of $0.5944 \mathrm{~cm}$. The tip used on all other patients has a diameter of $0.5000 \mathrm{~cm}$.

It should be kept in mind that what is called full extension of the drop does not correspond to the greatest length which the drop may have, but to the greatest length which it may have without becoming unstable. Almost immediately after the drop becomes unstable, the neck of the drop narrows with great rapidity; that is, the drop pinches off by a lateral movement of its upper surface (fig. 2).

It was found that the use of a period of about seven minutes gave the minimum drop weight. If held longer than seven minutes, the drop weight seems to rise again, but this rise is probably due to the formation of a solid film. Thus, a sample which gave a drop weight of 0.05742 for a set of drops each held for a period of from 4 to 8 minutes, gave a drop weight of 0.05790 for a drop held twenty-one minutes. Table 1 shows a comparison between drops held seven 

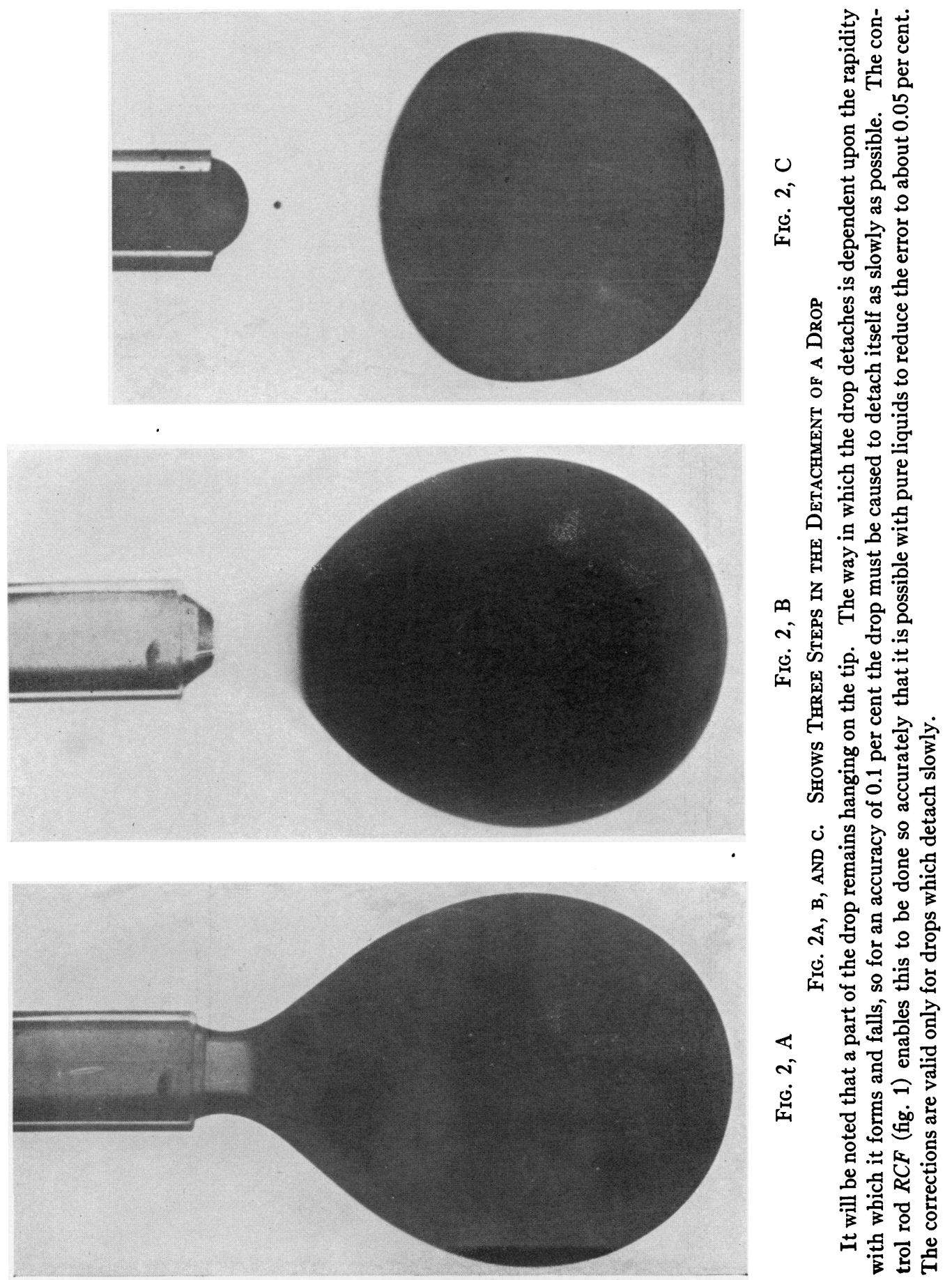
minutes and those held a shorter time. Since the time used to obtain a single drop is seven minutes, it was considered advisable to use only 2 to 3 drops per determination. It may be noted that Morgan and Woodward used only a single drop.

\section{CALCULATION OF THE SURFACE TENSION}

The surface tension $(\gamma)$ is not, as is often assumed, proportional to the weight of the drop when a single tip is used, but it may be calculated very easily from the following equation:

$$
\gamma=\frac{m g}{R} \times F
$$

in which $m$ is the weight in grams of the drop which falls (as weighed

TABLE 2

Drop-weight surface tension corrections

(Factor for multiplication $=F$.) $\quad$ Based on the value 72.75 as the surface tension of water at $20^{\circ} \mathrm{C}$. $R$ is the radius of the tip.

\begin{tabular}{c|l||l|l}
\hline$\frac{V}{R^{2}}$ & \multicolumn{1}{|c|}{$F$} & $\frac{V}{R^{3}}$ & $F$ \\
\cline { 2 - 3 }$(\infty)$ & 0.159 & 2.637 & 0.26224 \\
5000.0 & 0.172 & 2.3414 & 0.26350 \\
250.0 & 0.198 & 2.0929 & 0.26452 \\
58.1 & 0.215 & 1.8839 & 0.26522 \\
24.6 & 0.22561 & 1.7062 & 0.26562 \\
17.1 & 0.23051 & 1.5545 & 0.26566 \\
13.28 & 0.23522 & 1.4235 & 0.26544 \\
10.29 & 0.23976 & 1.3096 & 0.26495 \\
8.190 & 0.24398 & 1.2109 & 0.26407 \\
6.662 & 0.24786 & 1.124 & 0.26324 \\
5.522 & 0.25135 & 1.048 & 0.2617 \\
4.653 & 0.25419 & 0.980 & 0.2602 \\
3.975 & 0.25661 & 0.912 & 0.2585 \\
3.433 & 0.25874 & 0.865 & 0.2570 \\
2.995 & 0.26065 & & \\
\hline
\end{tabular}

in the gas or vapor in which it was suspended), $g$ is the gravitational attraction, and $R$ is the radius of the circular face of the tip.

The values of $F$ have been determined by Harkins and Brown, and are given in table 2, in which $V$ represents the volume of the drop which falls, and $V=\frac{m}{\rho}$ in which $\rho$ is the density of the liquid. 


\section{METHOD AND RESULTS}

A large part of the work consisted in evolving a method which would give constant results. The data which were obtained by the procedure finally chosen will be discussed in the next section. The preliminary steps in the method are listed below.

TABLE 3A

The surface tension of the serum falls to a more or less constant value in the first few hours after procuring the blood

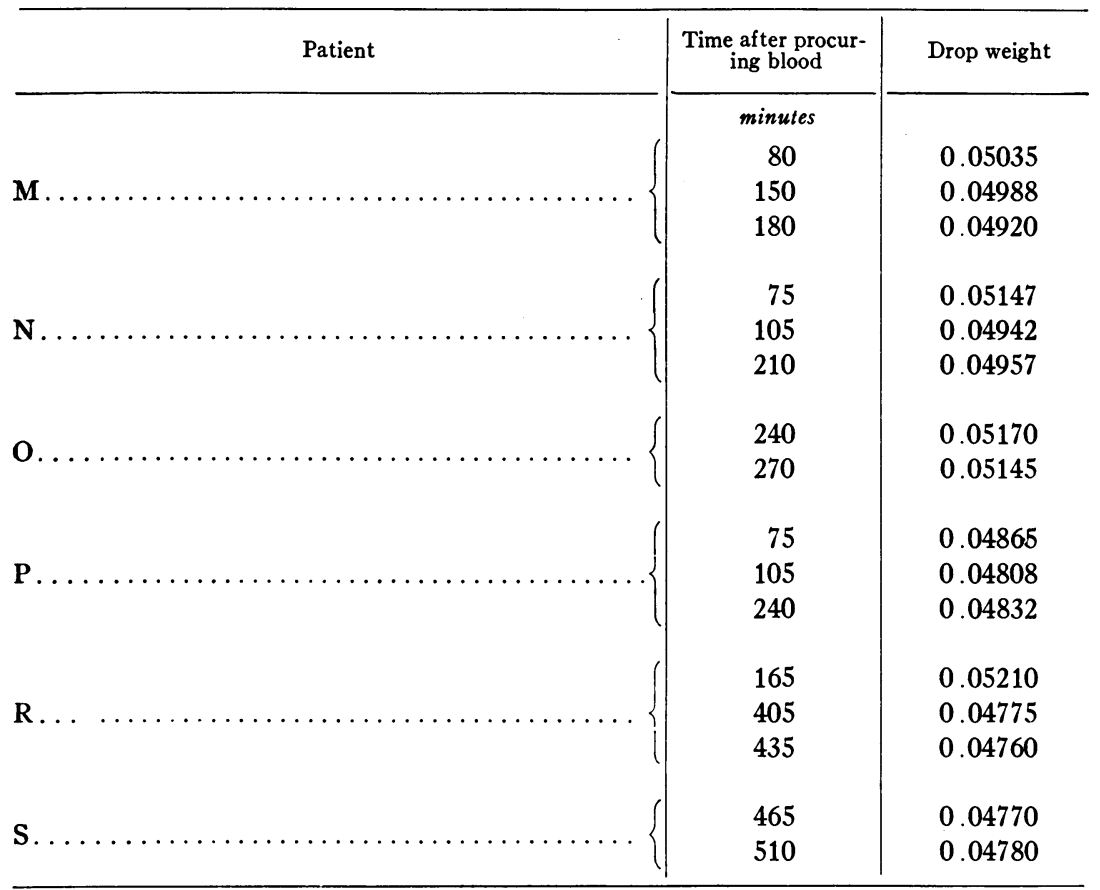

Note: The centrifuging was done about twenty minutes before the first determination recorded in each case, the blood being kept sealed until the centrifuging. In cases $\mathrm{N}$ and O no centrifuging was necessary.

1. Procuring the blood. About 10 to $20 \mathrm{cc}$. of blood is taken from the median cubital vein of either arm by means of a hypodermic syringe. The syringe must be dry since water, ether, and similar substances cause hemolysis and there is a possibility that hemoglobin in solution may affect some of the measurements involved. 
2. Sealing the tube. If the determinations cannot be made immediately, the blood should be sealed in a tube which it almost fills, so as to be in contact with as little air as possible. The tube may be stoppered with a paraffined cotton plug but is preferably sealed by the use of a minute flame. If the latter method is used, the tube should be drawn out to a fine point at one end before introducing the blood. Then only a slight heating will finish the seal. It is well not

TABLE 3B

The surface tension of samples of serum kept for varying periods of time (sealed, at $5^{\circ} \mathrm{C}$.) before centrifuging

\begin{tabular}{|c|c|c|c|c|c|}
\hline Patient & $\begin{array}{c}\text { First } \\
\text { determina- } \\
\text { tion drop } \\
\text { weight }\end{array}$ & Interval & $\begin{array}{l}\text { Second } \\
\text { determina- } \\
\text { tion drop } \\
\text { weight }\end{array}$ & Interval & $\begin{array}{l}\text { Third } \\
\text { determina- } \\
\text { tion }\end{array}$ \\
\hline & & days & & days & \\
\hline M. & 0.04920 & 1 & 0.04875 & 2 & 0.04788 \\
\hline N... & 0.04942 & 1 & 0.04900 & 3 & 0.05000 \\
\hline $0 \ldots \ldots$ & 0.05145 & 4 & 0.05235 & 3 & 0.04860 \\
\hline P... & 0.04808 & 1 & 0.04860 & & \\
\hline Q... & 0.04810 & 1 & 0.04848 & & \\
\hline S... & 0.04770 & 1 & 0.04932 & & \\
\hline
\end{tabular}

TABLE 3C

The lowering of the surface tension of serum on standing for several days

\begin{tabular}{|c|c|c|c|}
\hline Patient & $\begin{array}{c}\text { First deter- } \\
\text { mination drop } \\
\text { weight }\end{array}$ & Interval & $\begin{array}{l}\text { Second deter- } \\
\text { mination drop } \\
\text { wwight }\end{array}$ \\
\hline & & days & \\
\hline D. & 0.06509 & 4 & 0.06260 \\
\hline 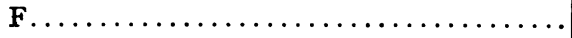 & 0.05742 & 2 & 0.05510 \\
\hline
\end{tabular}

to have the blood come quite to the end of the tube in this case, as it is difficult to seal glass covered with blood.

3. The interval between the procuring of the blood and the observations. The interval between the procuring of the blood and the determination has been observed to be of the greatest import. In general, other things being equal, several types of variation with time occur. These will be discussed in order:

$a$. If the blood is centrifuged immediately, and the determinations 
made at once, it is observed that the surface tension decreases rapidly within the first few hours to a more or less constant value. This is demonstrated by table $3 \mathrm{~A}$ which gives all the data that concern this phenomenon.

$b$. If the blood is kept sealed, without centrifuging for several days, there is no definite change in the surface tension. This is determined by sealing several different portions of the same sample of blood in separate tubes, and opening, centrifuging, and finding the surface tension of the serum from one tube each day. Table 3B shows that the surface tension of a serum may increase or decrease or vary irregularly with the time the separate samples are kept.

$c$. After being centrifuged, the surface tension of serum decreases gradually over a period of days as is seen in table 3C.

$d$. If blood is kept for several days in a sealed tube and then centrifuged, it exhibits a rapid decrease in surface tension to a more or less constant value during the first few hours, which decrease is usually not as large as that observed in $(a)$. This is shown in table 4.

4. Cleaning the apparatus. The apparatus is cleaned by sucking water through it immediately after the completion of the day's work. The serum should not be allowed to dry on the apparatus, nor should it be cleaned with alcohol, ether, or cleaning mixture as these reagents precipitate the proteins in the serum and clog the capillary.

5. Determinations of density and refractive index. The density was determined by the Hammerschlag method (15), and the refractive index was determined by the use of a Bausch and Lomb Abbé Refractometer.

6. The aeration of the serum. Alveolar air is blown through a long coiled tube immersed in the thermostat and into the serum through the tube mentioned above. This tube is first carefully flushed out with alveolar air from the experimenter's lungs before immersing the lower end of the short tube in the serum. When the tube is well flushed out, the distal end is dipped into the serum and alveolar air bubbled through for some time. This is done to secure equilibrium between the serum and a gas of constant composition approaching as nearly as possible that in the lungs. Saturation with alveolar air causes varying effects depending on the previous condition of the serum. In general the surface tension is lowered as is seen in table 5. 
TABLE 4

The surface tension of blood serum kept at $5^{\circ} \mathrm{C}$. for several days

Note that the tension falls to a more or less constant value in the first few hours after centrifuging.

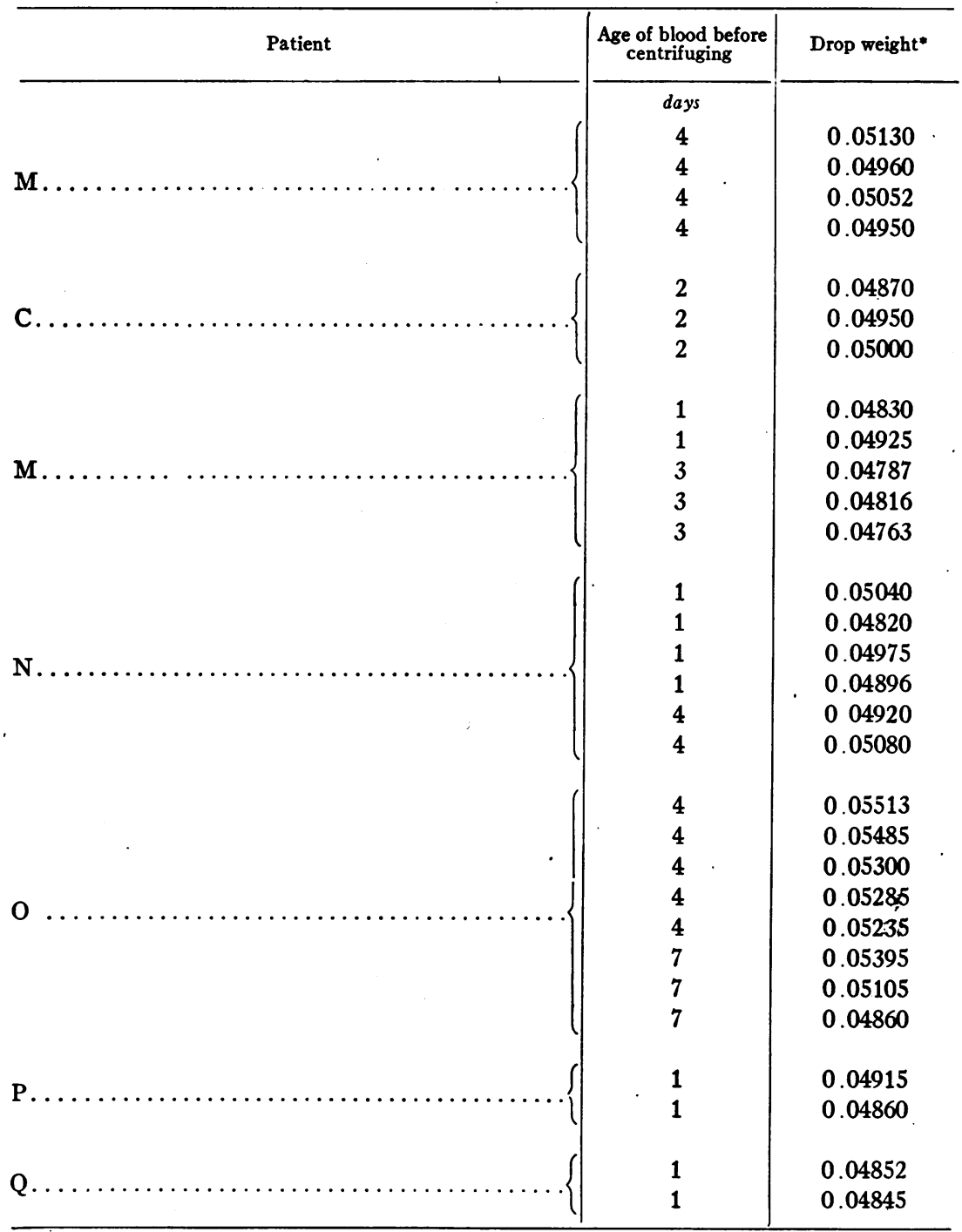

* For each sample the determinations are listed in order and were performed at one-half hour intervals. 


\section{THE TEMPERATURE COEFFICIENT}

Due to the fact that many of the determinations were made at the Presbyterian Hospital where there is no thermostat, it was necessary to determine the temperature coefficient of the surface tension of serum. These observations were made on the blood of Patient S, an almost normal subject. The results obtained at four temperatures from $10^{\circ}$ to $37^{\circ} \mathrm{C}$. are exhibited in table 6 .

TABLE 5

Effect of aeration with alveolar air upon the surface tension of the serum Patient D

\begin{tabular}{c|c}
\hline Drop weight before aeration & Drop weight after aeration \\
\cline { 2 - 2 } 0.06787 & 0.06509 \\
0.06743 & 0.06574 \\
\hline
\end{tabular}

TABLE 6

The temperature coefficient of serum surface tension

\begin{tabular}{c|c|c}
\hline Temperature & Drop weight & Surface tension \\
\cline { 2 - 3 }${ }^{\circ} \mathrm{C}$. & & \\
10 & 0.05340 & 54.26 \\
20 & 0.04932 & 50.35 \\
30 & 0.04645 & 47.58 \\
37 & 0.04505 & 46.22 \\
\hline
\end{tabular}

\section{PATHOLOGICAL VARIATIONS}

The results are not of such a nature that any definite conclusions can be drawn as to a lowering or raising of the surface tension as a result of any pathological condition. Many of the cases had several pathological factors, any one of which might have altered the surface tension. Furthermore the work of Brinkman (8) on oxalated plasma and of Zunz (9) on serum indicates that the surface tension is higher in women than in men. Until these results are confirmed or disproved, it would be best to allow a margin of error in comparing the serum surface tension of men and women.

The results in relation to the pathology of the different patients are shown in table 7 . In most cases the corresponding density and 
refractive index are given. It is apparent that no two sets of these results run perfectly parallel. The surface tension is observed to be

TABLE 7

The surface tension of blood serum as related to the pathology of the patients from whom the blood was obtained

Temperature $=20^{\circ} \mathrm{C}$.

\begin{tabular}{|c|c|c|c|c|}
\hline Patient & Diagnosis & $\begin{array}{l}\text { Surface } \\
\text { tension }\end{array}$ & $\begin{array}{c}\text { Refractive } \\
\text { index }\end{array}$ & Density $\dagger$ \\
\hline I & Normal & 53.55 & & 56 \\
\hline $\mathbf{J}$ & Normal & 51.01 & & 2 \\
\hline $\mathbf{K}$ & Normal & 51.02 & & 2 \\
\hline $\mathbf{L}$ & Diabetes & 53.93 & & 0 \\
\hline $\mathbf{M}$ & $\begin{array}{l}\text { General paresis, given typhoid treatment for } \\
\text { syphilis few days before, collapsed after spi- } \\
\text { nal puncture elsewhere, male, } 36 \text { years }\end{array}$ & 50.41 & 20 & 42 \\
\hline $\mathbf{M}$ & A week later & 49.71 & 38 & 44 \\
\hline $\mathrm{C}$ & $\begin{array}{l}\text { Chronic interstitial nephritis, arterial hyper- } \\
\text { tension, } 7 \text { successful pregnancies, bad ver- } \\
\text { tigo, albumin, epistaxis, stroke in Novem- } \\
\text { ber, 1925, good renal efficiency, female, } 40 \\
\text { years }\end{array}$ & 50.43 & 8 & 20 \\
\hline $\mathbf{N}$ & $\begin{array}{l}\text { Parenchymatous nephritis, hemoglobin of } \\
28 \text { per cent, red blood cells of } 2,500,000 \text {, } \\
\text { female, } 40 \text { years }\end{array}$ & 50.52 & 3 & 25 \\
\hline $\mathbf{O}$ & $\begin{array}{l}\text { Sciatica, chronic sacroiliac arthritis, chronic } \\
\text { tonsilitis, female, } 42 \text { years }\end{array}$ & 51.77 & 16 & 33 \\
\hline $\mathbf{P}$ & $\begin{array}{l}\text { Paroxysmal tachycardia of migraine, acute } \\
\text { cold, male } 40 \text { years }\end{array}$ & 49.37 & 15 & 32 \\
\hline $\mathbf{Q}$ & $\begin{array}{l}\text { Trigone cystitis, cells in kidney urines, bad } \\
\text { cold, colored, male, } 45 \text { years }\end{array}$ & 49.37 & 27 & 53 \\
\hline $\mathbf{R}$ & $\begin{array}{l}\text { Parenchymatous nephritis, myocarditis, fat, } \\
\text { female } 39 \text { years }\end{array}$ & 48.70 & 16 & · 28 \\
\hline $\mathrm{S}$ & $\begin{array}{l}\text { Bad case of influenza three weeks before. } \\
\text { Wasserman }++++6 \text { years ago, negative } \\
\text { since, anemia, male, } 48 \text { years }\end{array}$ & 49.57 & 0 & 8 \\
\hline
\end{tabular}

* For simplicity the refractive index tabulated above is the number of ten thousandths the refractive index exceeds 1.390 .

† Similarly, the densities are expressed as ten thousandths above 1.0222, the lowest value.

low in the cases just recovering from influenza; and in neither of the two cases suffering from parenchymatous nephritis, both of whom are women, is the surface tension quite as high as the average. This 
latter result would tend to agree somewhat with the results of Clausen (10). But as Clausen gives no data in support of his conclusion, it is not known how much lowering of surface tension was obtained in parenchymatous nephritis. The high value of tension in the single diabetic case is interesting.

THE RING METHOD FOR THE DETERMINATION OF THE SURFACE TENSION OF BLOOD SERUM

The ring method has been used in an enormous number of the determinations of surface tension carried out with blood serum or solutions of blood serum in water. In nearly all cases the results obtained are almost valueless, since errors of 20 per cent are not uncommon. Such results are in general incorrect from even the relative standpoint, since the errors are highly variable.

1. The calculation of the surface tension. The most common error in the use of the ring method is that made in the calculation of the surface tension. The surface tension is calculated from the pull exerted by the surface of the liquid on a circular ring (of radius $R$ ) of circular wire (of radius $r$ ). What is usually determined is the maximum pull $(W)$ on the ring as determined by a torsion balance, or better by the proper type of analytical or assay balance. This pull is obtained by allowing the horizontal ring to come into contact with the surface and then lowering the liquid or raising the balance until the film of liquid upheld by the ring is ruptured. It is customary to consider the maximum pull $(P)$ per centimeter of surface attached to the wire to be defined by the equation

$$
P=\frac{W g}{4 \pi R}
$$

It is obvious that the surface tension $(\gamma)$ is given by the identity

$$
\gamma=P \frac{\gamma}{P} \text { or } \quad \gamma=P F
$$

In order that equation (2) may be used for the calculation of the surface tension of the liquid the values of the ratio $\left(\frac{\gamma}{P}\right.$ or $\left.F\right)$ must be known. These values might have been calculated from theory, but 
this has not as yet been done. The values of this ratio were determined by Harkins, Young and Cheng (16), and more carefully later by Harkins and Jordan (17). The values of this fraction as now known seem to be accurate to within 0.3 per cent, which gives considerable accuracy to the ring method, though it is still less accurate than the drop weight method under the best conditions (error 0.1 per cent).

The values of the correction factor $F$ of the equation

$$
\gamma=\frac{W g}{4 \pi R} \cdot F
$$

are given in table 8. These correction factors are valid only if the ratio of the radius of the ring $(R)$ to that of the wire $(r)$ is 40 , which is the ratio most commonly used.

\section{TABLE 8}

Values of the correction factor $(F)$ of the ring method (Harkins and Jordan) for a ring in which $R=0.6366 \mathrm{~cm}$., $r=0.01570 \mathrm{~cm}$, and $R / r=40.55$

(This is the size of ring most generally used)

\begin{tabular}{l|l}
\hline$\frac{R^{3}}{V}$ & $\gamma / P$ \\
\hline 0.43 & 0.988 \\
0.5 & 0.973 \\
0.6 & 0.954 \\
0.7 & 0.938 \\
0.8 & 0.925 \\
0.9 & 0.914 \\
1.0 & 0.905 \\
1.1 & 0.898 \\
1.2 & 0.892 \\
\hline
\end{tabular}

The correction factor $(F)$ is a function of $\frac{R^{3}}{V}$ in which $V$ is the volume of liquid lifted by the pull $(W)$ of the ring above the level of the plane portion of the sufficiently large surface of the liquid, so

$$
V=\frac{W g}{\rho}
$$

in which $\rho$ is the density of the liquid.

In order to determine the surface tension the value of the total 
pull $(W)$ is first determined by the balance. From this $(P)$ is calculated by substituting the mean radius $(R)$ of the ring in equation (1), and the volume $(V)$ is calculated from equation (4). The value of $\frac{R^{3}}{V}$ is then calculated, and from this the value of $\frac{F}{\gamma}$

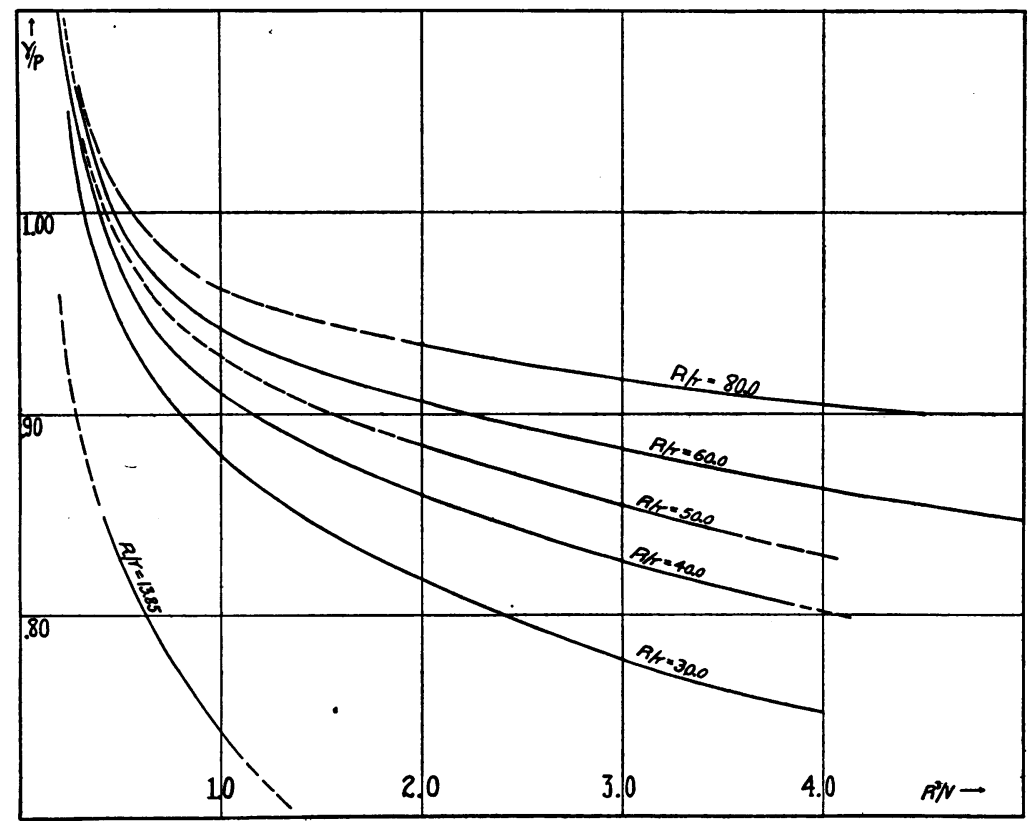

Fig. 3. Correction Curve for the Determination of the Surface Tension of a Liquid By the Ring Method

Ordinates $=$ values of $F . \quad$ Abscissae $=$ values of $R^{3} / V . \quad$ The curves beginning at the bottom represent rings for which the values of the radius $(R)$ of the ring, divided by the radius $(r)$ of the wire are respectively: $13.85,30,40,50,60$, and 80 . $R$ is in centimeters.

$\gamma$, surface tension; $P, \mathrm{Wg} / 4 \pi R ; R$, radius of ring; $r$, radius of wire; $V$, volume of liquid suspended by the upward pull of the ring.

is obtained by table 8. From this the surface tension $\gamma$ is obtained by equation (3). Any simpler general method gives incorrect results.

The value of the correction factor $(F)$ varies also with the value of the ratio $\frac{R}{r}$ as shown by figure 3 . Table 8 gives the correction factors 
which correspond with the fourth curve from the top. Any number of rings whose correction factors lie on this single curve may be used: the only condition is that the radius of the ring shall be 40 times the radius of the wire, and that the ring shall be circular, plane, and, when suspended, perfectly horizontal.

2. Area of the surface. The area of the surface of the liquid from which the ring is pulled should be large enough to meet the following condition: just before the detachment of the ring there must be an annular ring of surface, completely around the ring of wire, in which the liquid surface is plane. The larger the ring of wire, the larger the total surface should be. The form of surface which is most economical of liquid is that of a circle, and for small rings this should be about $7 \mathrm{~cm}$. in diameter.

3. Surface tension and time. What is commonly designated as the surface tension of a liquid is the equilibrium value. It has been seen (page 267) that the time necessary to obtain equilibrium with undiluted blood serum is about seven minutes. With diluted serum this time may be more than an hour.

The surface tension of blood serum cannot be obtained by allowing the serum to stand in a vessel for the time given above (seven minutes for undiluted serum) and then pulling the ring from the surface. The correct procedure is as follows: blood serum is placed in the vessel and as quickly as possible the ring is placed in contact with its surface and at once the ring is lifted to just that distance above the serum, which at the end of the correct interval to give complete adsorption (seven minutes for undiluted serum), corresponds with the beginning of instability. In other words the surface must be fully extended initially and allowed to break without further extension at the end of the proper period.

In order that this may be done preliminary trials should be made to determine the proper extension, or different extensions may be applied and the pull $(W)$ plotted against the time $(t)$ of the rupture.

4. Adjustmeni of the ring. It has been shown by Harkins and Jordan (17) that it is essential to adjust the ring in such a way that when it hangs from the balance its plane shall be horizontal. This has been done by obtaining the image of the ring in a plane horizontal mirror of gold or silver placed just below it. 


\section{SUMMARY}

1. The surface tension of normal blood serum is found to be about 52 dynes per centimeter at $20^{\circ} \mathrm{C}$., and 48 dynes at $37^{\circ}$, and the surface tensions under certain pathological conditions have been determined. On the whole the values are lower than for normal serum. The purpose of the work of the paper has been to develop proper methods for the determination of the surface tension of biological liquids, rather than to secure a large number of data.

2. The worthlessness of the earlier work on the surface tension of blood serum is found to be due to (a) failure to obtain equilibrium conditions, or (b) improper methods of calculation.

3. An apparatus for the determination of the surface tension of biological liquids by the drop weight method has been developed, together with a new method for the control of the drop in such a way as to give accurate results.

4. The methods used in procuring the blood and in sealing up the serum are described.

5. The effects upon the surface tension of the time, before and after centrifuging, have been investigated.

6. Saturation of the serum with alveolar air at $20^{\circ} \mathrm{C}$. is found to lower the surface tension by about 2 dynes.

7. Correction tables for the calculation of the surface tension by $(a)$ the drop weight method, and $(b)$ the ring method, are given. The almost universal failure to use these corrections has caused earlier work to be of little value.

8. A method is given for the use of the ring method in the determination of the surface tension of biological liquids. The conclusion is reached that the drop weight method is somewhat superior to the ring method for such a purpose when both are properly used.

The writers wish to thank Drs. Wilber E. Post and William A. Thomas for suggesting this problem and for advice concerning it.

\section{BIBLIOGRAPHY}

1. Buglia, G., Biochem. Ztschr., 1908, xi, 311. Veränderungen der Oberflächenspannung des Blutserums unter dem Einfluss von verschiedenen Elektrolyten. 
2. Fillipi, E., Lo sperimentale, 1909, lxiii, 373. Su I Rapporti Tra I Mutamenti della Viscosita e della Tensione Superficiale del Sangue Vivente Sotti L'Influenza di Varii Farmaci.

3. Iscovesco, H., Compt. rend. Soc. d. Biol., 1911, lxx, 66. Etudes stalagmométriques. La Tension superficielle du sérum sanguin.

4. Juhnke, L. A., Interstate Med. J., 1911, xviii, 233. The Meiostagmin Reaction.

5. Fano, G., and Mayer, d. M., Arch. di fisiol., 1907, iv, 165. Sulla tensione superficiale del siero di sangue.

6. Marghini, Francesco, Arch. farm. sper., 1912, xiii, 53. Experimental Studies on the Surface Tension of Blood Serum.

7. Morgan, J. L. R., and Woodward, H. E., J. Am. Chem. Soc., 1913, xxxv, 1249. The Weight of a Falling Drop and the Laws of Tate. XI. The Drop Weight and Surface Tension of Blood Serum.

8. Brinkman, R., Arch. neerland. physiol., 1922, vii, 258. Sur la tension superficielle du sang humain normal.

9. Zunz, M., and La Barre, J., Bull. Acad. Roy. Med. Belg., 1924, iv, 5th series, 74. Recherches sur la tension superficielle du plasma et du sérum humains à l'etat normal et dans la syphilis.

10. Clausen, S. W., Proc. Am. Soc. Biol. Chemists, J. Biol. Chem., 1924, lix, p. xlv. Studies in Parenchymatous Nephritis.

11. DuNouy, P. L., J. Exper. Med., 1925, xli, 663. Surface Tension of Serum. XII. A Technique for the Accurate Study of the Drop in Function of the Time. See also other papers in the same journal.

12. Marriott, McK., Proc. Inst. Med. Chicago, 1925, v, 231. Application of Recent Studies on Nature of Nephritis.

13. Harkins, W. D., and Brown, F. E., J. Am. Chem. Soc., 1916, xxxviii, 246. A Simple Apparatus for the Accurate and Easy Determination of Surface Tension.

14. Morgan, J. L. R., J. Am. Chem. Soc., 1911, xxxiii, 349. The Weight of a Falling Drop and the Laws of Tate. III. An Apparatus for Rapid and Accurate Determination of the Weight of a Falling Drop of Liquid.

15. Webster, R. W., Diagnostic Methods, Blakiston, 1923, 7th ed., p. 458.

16. Harkins, W. D., Young, T. F., and Cheng, L. H., Science, 1926, lxiv, 333. The Ring Method for the Determination of Surface Tension.

17. Harkins, W. D., and Jordan, H.F. Unpublished results on Accurate Corrections for the Ring Method for the Determination of Surface Tension. 